\title{
Effects of ursolic and oleanolic on SK-MEL-2 melanoma cells: In vitro and in vivo assays
}

\author{
ANGELA CAUNII $^{1 *}$, CAMELIA OPREAN $^{1,2^{*}}$, MIRABELA CRISTEA $^{2}$, ALEXANDRA IVAN $^{2,3}$, CORINA DANCIU $^{1}$, \\ CALIN TATU $^{2,3}$, VIRGIL PAUNESCU ${ }^{2,3}$, DANIELA MARTI ${ }^{4}$, GEORGE TZANAKAKIS ${ }^{5}$, \\ DEMETRIOS A. SPANDIDOS ${ }^{5}$, ARISTIDES TSATSAKIS ${ }^{3,5}$, RAZVAN SUSAN ${ }^{3}$, \\ CODRUTA SOICA $^{1}$, STEFANA AVRAM $^{1 *}$ and CRISTINA DEHELEAN ${ }^{1}$
}

${ }^{1}$ Faculty of Pharmacy, 'Victor Babeş' University of Medicine and Pharmacy, 300041 Timişoara; ${ }^{2}$ 'Pius Brinzeu' Timișoara County Emergency Clinical Hospital, Oncogen Institute, 300723 Timişoara; ${ }^{3}$ Faculty of Medicine, 'Victor Babeş' University of Medicine and Pharmacy, 300041 Timişoara; ${ }^{4}$ Faculty of Medicine, Western University Vasile Goldis, Arad 310025, Romania; ${ }^{5}$ Faculty of Medicine, University of Crete, 71003 Heraklion, Crete, Greece

Received July 7, 2017; Accepted October 2, 2017

DOI: $10.3892 /$ ijo. 2017.4160

\begin{abstract}
Among the triterpenoids, oleanolic acid (OA) and its isomer, ursolic acid (UA) are promising therapeutic candidates, with potential benefits in the management of melanoma. In this study, we aimed to examine the in vitro and in vivo anti-invasive and anti-metastatic activity of OA and UA to determine their possible usefulness as chemopreventive or chemotherapeutic agents in melanoma. For the in vitro experiments, the anti-proliferative activity of the triterpenic compounds on SK-MEL-2 melanoma cells was examined. The anti-invasive potential was assessed by testing the effects of the active compound on vascular cell adhesion molecule (VCAM) and intercellular adhesion molecule (ICAM) adhesion to melanoma cells. Normal and tumor angiogenesis were evaluated in vivo by chicken embryo chorioallantoic membrane (CAM) assay. The two test triterpenoid acids, UA and OA, exerted differential effects in vitro and in vivo on the SK-MEL-2 melanoma cells. UA exerted a significant and dose-dependent anti-proliferative effect in vitro, compared to OA. The cytotoxic effects in vitro on the melanoma cells were determined by the examining alterations in the cell cycle phases induced
\end{abstract}

Correspondence to: Dr Camelia Oprean, Department of Environmental and Food Chemistry, Faculty of Pharmacy, 'Victor Babeş' University of Medicine and Pharmacy, 2nd Eftimie Murgu Square, 300041 Timişoara, Romania

E-mail: camelia.oprean@umft.ro

Professor Aristides Tsatsakis, Faculty of Medicine, University of Crete, 71003 Heraklion, Crete, Greece

E-mail: tsatsaka@uoc.gr

*Contributed equally

Key words: oleanolic acid, ursolic acid, anti-invasive, anti-angiogenic, melanoma by UA that lead to cell arrest in the $\mathrm{S}$ phase. Moreover, UA was found to affect SK-MEL-2 melanoma cell invasiveness by limiting the cell adhesion capacity to ICAM molecules, but not influencing their adhesion to VCAM molecules. On the whole, in this study, by assessing the effects of the two triterpenoids in vivo, our results revealed that $\mathrm{OA}$ had a greater potential to impair the invasive capacity and tumor angiogenesis compared with UA.

\section{Introduction}

A recent article (2017) of the American Cancer Society presenting key statistics for cutaneous melanoma reported that among all types of malignancies, skin cancer is the most common (1). Although squamous cell carcinoma (SCC) and basal cell carcinoma (BCC) are more frequent, melanoma, the so-called cancer of the Western world, accounts for approximately $1 \%$ among all types of skin cancers. The aggressiveness of this particular skin pathology is due to its highly metastatic potential and increased resistance to chemotherapeutic agents, events associated with a low survival of affected patients $(2,3)$. When localized to the primary site, the chances of cure are high; however, after it develops and reaches the lymph nodes, the prognosis becomes poor, with the 5-year survival rate being around $29 \%$. The marked decrease in survival presents once the major organs are invaded by malignant cells, with the 5 -year survival rate reaching only about $7 \%$ (4). As regards therapeutic strategies, the treatment approach is straightforward in the early stages of the disease when the tumor is localized, and involves the wide excision of the primary tumor site. The challenges in treatment strategies present once metastasis occurs. Chemotherapy, radiation therapy, immunotherapy and targeted therapy represent current standard approaches for the management of this highly aggressive disease, with varying results (5-7).

The high mortality rates associated with the disease are due to its heterogenous molecular pattern based on multiple progressive mutations that can occur. The most frequent 
subtype of malignant melanoma, found in $40-50 \%$ of cases, harbors the oncogene mutation, B-RAF V600, which is related to sun exposure. It is followed by a mutation of the oncogene N-RAS, detected in $15-20 \%$ of patients. However, although this mutation exhibits significant frequency, its' effect has not yet been widely studied and the response to the few treatment options is relatively poor (8-10). Based on these data, in this study, in order to investigate possible targeted new therapeutics, we decided to investigate the SK-MEL-2 melanoma cell line that harbors two mutant genes, N-RAS and TP53.

Currently, for the development of treatment options, natural compounds are intensively investigated for their chemopreventive and anti-invasive potential, in addition to lower secondary effects $(11,12)$. Angiogenesis, the process through which new blood vessels are formed from pre-existing ones, is one of the key steps in tumor growth and metastasis. This process is being highly investigated as a possible therapeutic approach in cancer, after Folkman et al (13) introduced the concept of tumor angiogenesis.

The discovery of novel drugs from natural sources targeting cancer and angiogenesis was first based on the traditional practices of treating vascular-dependent pathologies (14). As an unbalanced type of diet is increasingly associated with cancer pathologies, a growing number of natural compounds found in healthy diet foods is being evaluated as anticancer agents (15). An important class of phytochemicals with demonstrated anticancer potential is represented by the triterpenoids. Triterpenoid compounds are secondary metabolites widely distributed in plants. Structurally, they are formed by 30 atoms of carbon, organized in isoprene units. Important triterpenoids are derivatives of the pentacyclic carbon skeleton, including lupane (e.g., betulinic acid), oleane [e.g., oleanolic acid (OA)] and ursane [e.g., ursolic acid (UA)]. Several representatives are known for their potential therapeutic benefits as antioxidant, anti-inflammatory, anti-bacterial, anti-malaria and anti-viral agents. Importantly, anticancer properties have been attributed to these compounds in various types of cancer cell lines, in which they have been shown toexert anti-proliferative, pro-apoptotic and tumor anti-invasive effects (16-19).

Among the triterpenoids OA (3-beta-3-hydroxy-olean-12ene-28-oic-acid) and its isomer, UA (3-beta-3-hydroxy-urs-12ene-28-oic-acid) (Fig. 1), are promising therapeutic candidates. They are highly abundant in edible plant foods, such as apples, pears, olives or aromatic plants from the Lamiaceae family, such as oregano, basil, rosemary or lemon balm (20-23). The pharmacological value of the two compounds is demonstrated both by the multiple pharmacological targets, but also by their low toxicity $(24,25)$. To date, the various pharmacological effects of UA and OA exerted via multiple mechanisms are not yet fullycompletely understood. Thus, they are the subject of current research.

Despite structural similarities, the effectiveness of their anticancer activity differs. Some studies have reported an increased antitumor activity both in vitro and in vivo for UA, but OA has also been assigned with anticancer properties $(26,27)$. Hence, the selection of one of the two triterpenic compounds for cancer chemoprevention should be carried out taking into account the involved cancerous cell line and/or target molecules engaged in each type of cancer (28). Some available data suggest the potential benefits of OA and UA in the management of melanoma. In vitro, various $\mathrm{IC}_{50} / \mathrm{EC}_{50}$ values for OA and UA have been obtained for several melanoma cell lines (29-31).

MAP/extracellular signal-regulated kinase (MEK) protein kinases form a family of proteins that next to mammalian target of rapamycin (mTOR), are involved in cell proliferation, survival, differentiation and angiogenesis, and are considered interesting synergistic targets for N-RAS mutated cancers (8). Modern approaches for the discovery of active compounds involve the virtual screening of large natural compound databases against druggable targets in cancer (32-34). In this study, for the selection of the two triterpenic compounds, we considered the availability from natural sources and their promising anticancer activities. Moreover, recent studies have indicated the possible role of UA and OA in modulating some of the deregulated kinases involved in the progression of various types of cancer $(35,36)$. However, the mechanisms of action and the potential effects in vivo in N-RAS-mutated melanoma of the two compounds are not yet fully understood.

The tumor microenvironment, as regards tumor-associated inflammation and angiogenesis, as well as specific targets, has been intensively studied $(18,19,37-39)$ in order to elucidate the mechanism(s) of action of triterpenic compounds. In the present study, we aimed to test the in vitro and in vivo anti-invasive and anti-metastatic activity of OA and UA to determine their possible use as chemopreventive or therapeutic agents in melanoma. For the in vitro experiments, the anti-proliferative activity of the triterpenic compounds on SK-MEL-2 melanoma cells was examined. The anti-invasive potential was assessed by examining the effects of the active compounds on vascular cell adhesion molecule (VCAM) and intercellular adhesion molecule (ICAM) adhesion to melanoma cells. Normal and tumor angiogenesis was evaluated in vivo by chicken embryo chorioallantoic membrane (CAM) assay.

\section{Materials and methods}

\section{In vitro analysis}

Cell culture. The SK-MEL-2 human melanoma cells (ATCC, Manassas, VA, USA) were cultured in Eagle's minimum essential medium (EMEM), containing 10\% fetal bovine serum (FBS) (both from ATCC) and 1\% penicillin-streptomycin (Pen/Strep, 10,000 IU/ml; PromoCell, Heidelberg, Germany). The cells were maintained in an atmosphere of $5 \% \mathrm{CO}_{2}$ at $37^{\circ} \mathrm{C}$.

In vitro cell proliferation assay:AlamarBlue assay. The SK-MEL-2 cells were seeded in 96-well microplates (5,000 cells/plate) and incubated overnight in order to allow attachment of the cells to the bottom of the plate. Subsequently, $150 \mu \mathrm{l}$ of fresh EMEM medium containing UA or OA was added and the cells were incubated for $48 \mathrm{~h}$. UA or OA was added at concentrations between 25 and $100 \mu \mathrm{M}$. After $48 \mathrm{~h}$, $15 \mu \mathrm{l}$ of AlamarBlue solution were added and the cells were incubated for $4-10 \mathrm{~h}$ at $37^{\circ} \mathrm{C}$. The samples were spectrophotometrically analyzed at 570 and $600 \mathrm{~nm}$ using an $\mathrm{xMark}^{\mathrm{TM}}$ Microplate Spectrophotometer (Bio-Rad, Hercules, CA, USA). Wells with untreated cells were used as controls. The test substances were dissolved in dimethyl sulfoxide (DMSO; Sigma-Aldrich, Ayrshire, UK) and stock solutions were stored at $2-8^{\circ} \mathrm{C}$. The final concentrations were prepared by diluting the 


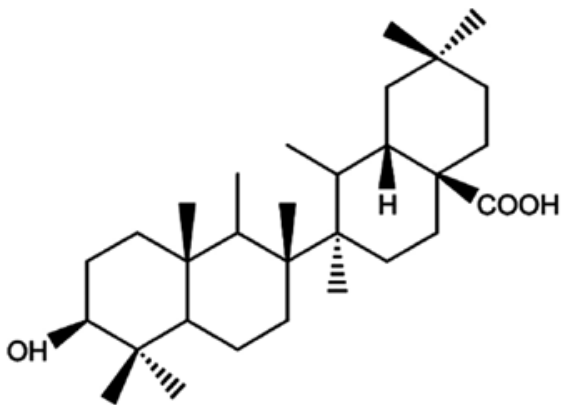

Oleanolic acid

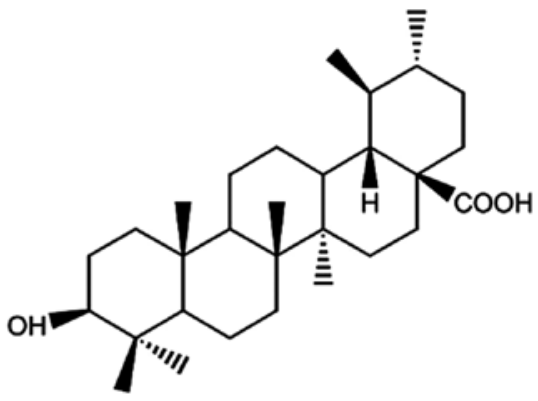

Ursolic acid

Figure 1. Chemical structures of oleanolic acid and ursolic acid.

stock solution with the EMEM growth medium. The highest DMSO concentration $(0.1 \%)$ of the medium did not exert any significant effect on cell proliferation. The experiments were performed using microplates with at least 4 parallel wells. The results are presented as the mean value \pm standard deviation. One-way ANOVA was used to determine statistically signficant differences between various experimental groups.

Cell cycle analysis. The SK-MEL-2 human melanoma cells were seeded in $25 \mathrm{~cm}^{2}$ plates $\left(10^{6}\right.$ cells/plate $)$ and treated with UA and OA $(30,50$, or $75 \mu \mathrm{M})$. After $48 \mathrm{~h}$ of treatment, the cells were collected, fixed with cold $70 \%$ ethanol and stored for $30 \mathrm{~min}$ at $4^{\circ} \mathrm{C}$. Following centrifugation $\left(1,500 \mathrm{rpm}, 22^{\circ} \mathrm{C}\right)$, cold PBS was used to wash the cells. Subsequently, $50 \mu 1$ of propidium iodide (concentration, $50 \mu \mathrm{M}$ ) (BD Pharmingen; BD Biosciences, San Diego, CA, USA) were added to the cells and the cells were incubated for $10 \mathrm{~min}$ in the dark, in order to stain the DNA. A FACSCalibur flow cytometer (Becton-Dickinson, Franklin Lakes, NJ, USA) was used to perform the DNA content analysis. The percentage of cells present in the different cell cycle phases was determined using Modfit software.

Flowchamber assay. The SK-MEL-2 tumor cell lines were cultured according to the protocol described above. The cells were treated with 30 and $50 \mu \mathrm{M}$ of UA. After $48 \mathrm{~h}$ of treatment, the cells were harvested by trypsinization and the adhesive capacity of the cells exposed to mechanical stress (shearstress) on the VCAM and ICAM substrates (R\&D Systems, Abingdon, UK) was evaluated using the flow chamber method.

Flowchamber analysis follows several consecutive steps beginning with the coating of the flowchamber channels with adhesion molecules (VCAM and ICAM), used at a concentration of $2 \mu \mathrm{l} / \mathrm{ml}, 30 \mu \mathrm{l} /$ channel $15 \mathrm{~min}$ prior to the beginning of the experiment ( 3 channels for each adhesion molecule). The cells were trypsinized and incubated while the peristaltic pump (Ismatec - IPC High Precision Multichannel Dispenser (IDEX Corporation, Glattbrugg, Switzerland) was prepared. The preparation of the peristaltic pump consists of assembling the tubulature, passing the HBSS medium (100 ml PBS with $\mathrm{Ca}^{2+}$ and $\mathrm{Mg}^{2+}, 50 \mathrm{ml}$ DMEM high glucose medium, $0.75 \mathrm{ml}$ BSA 20\%) through the tubes and fixating the flowchamber to the microscope connected to the camera. The tube is fixated in the 'OUT' position and to the 'waste' recipient. The supernatant in the 'IN' position is discarded.

In continuation, $100 \mu \mathrm{l}$ well omogenized cellular suspension ( $10^{5}$ cells) was inserted at the 'IN' end of the channel, after which the tube connecting to the pump was inserted. The cells were allowed $3 \mathrm{~min}$ to adhere to the substrate, after which, using a Leica ICC50HD camera (Leica, Bucharest, Romania) an image was acquired representing the START moment. After that moment, shearstress was introduced following this schedule: $0.35 \mathrm{dyne} / \mathrm{cm}^{2}-1 \mathrm{~min} ; 2$ dyne $/ \mathrm{cm}^{2}-30 \mathrm{sec}$; 5 dyne $/ \mathrm{cm}^{2}$ - $30 \mathrm{sec} ; 8$ dyne $/ \mathrm{cm}^{2}$ - $30 \mathrm{sec} ; 15 \mathrm{dyne} / \mathrm{cm}^{2}-30 \mathrm{sec}$. Following each time-speed period, an image was acquired using a Leica ICC50HD camera and Leica DMD108 microscope (Leica). At the end of the experiment, all images were analyzed in order to count the adhered cells at the initial moment and the remaining cells throughout the experiment. The cell number was correlated to the increase of shear stress. Variations of at least $15 \%$ from the total number of cells were considered significant in comparison to the control cells for the same flux values.

\section{In vivo analysis}

CAM assay. Fertilized eggs (Gallus gallus domesticus), obtained from a local poultry farm, were disinfected with $70^{\circ}$ ethanol, dated and subsequently incubated in a horizontal position, at constant humidity and $37^{\circ} \mathrm{C}$. On the third day of incubation, 3-4 $\mathrm{ml}$ of albumen was removed, so that the developing chorioallantoic membrane could be detached from the eggshell, and the blood vessels from the extra-embryonic vascular plexus could be easily observed. On the 4th day of incubation, a window was cut, resealed with adhesive tape, and set to incubate until the beginning of the experimental procedures, as previously described (40).

Evaluation of angiogenesis and tumor angiogenesis on the chorioallantoic membrane. The present study was conducted in ovo, beginning on the 7th day of incubation of the chick embryos. The effect of UA and OA on the process of angiogenesis of the chick embryo CAM was firstly evaluated in the absence of tumor cells between the 7th and the 11th embryonic days. During this interval, the vascular network is in a rapid growing phase, and the endothelial cells exhibit a high mitotic rate, similar to that of tumor-associated angiogenesis (41). The samples were tested at a concentration of $30 \mathrm{mM}$, using $3 \%$ DMSO. Three doses of the test samples and blank solutions containing only $3 \%$ DMSO were applied in triplicate daily for 5 days. Volumes of $5 \mathrm{ml}$ were added inside a plastic ring with a diameter of $5 \mathrm{~mm}$ previously placed on the CAM surface in vascularized areas and the specimens were returned for incubation. Evaluation was performed daily by means of 
a stereomicroscope and relevant images were captured for further analysis. Finally, on day 12 of incubation, the specimens were sacrificed and the fine CAMs were harvested.

The SK-MEL-2 cells were cultured according to the protocol described above. After harvesting the cells from the culture plate through trypsinization, the cells were resuspended in the culture medium until reaching the final concentration of $10^{5} / 3 \mu \mathrm{l}$. On the 10 th day of incubation, $3 \mu \mathrm{l}$ of the SK-MEL-2 melanoma cell suspension were inoculated inside a sterile ring previously placed on the CAM. The control samples were only inoculated with $3 \mu \mathrm{l}$ of cell culture medium.

UA, OA and blank (DMSO) solutions were added in volumes of $5 \mu \mathrm{l}$ inside the rings 1 day after the inoculation of the cells. Samples were applied daily for 5 days. The process was dynamically examined and relevant captures were saved. On the final day of the experiment, all the specimens were sacrificed and prepared for further histological analysis.

Zeiss Axio V16 stereomicroscope was used for the in ovo examination of the specimens. Images were registered by means of the Zeiss Axio Cam equipment and image analysis was done using Zeiss ZEN and Image $\mathrm{J}$ softwares. Morphometric analysis was applied on the stereomicroscopic photographs of the tested CAMs, using an arbitrary 0-5 scale that scores the intensity of vascular density on the area of application. Low values are correlated with a reduced angiogenic process, while the higher scores indicate an activated process. The results are expressed as mean values \pm standard deviation. Statistical analysis was performed using SPSS software (IBM SPSS Statistics for Windows, version 20.0; IBM Corp., Armonk, NY, USA).

\section{Results}

Effects of UA and $O A$ on the proliferation of SK-MEL-2 melanoma cells. Cell proliferation experiments demonstrated that UA exerted an inhibitory and dose-dependent effect on SK-MEL-2 human melanoma cell growth (Fig. 2), with an $\mathrm{IC}_{50}$ value of $58.43 \mu \mathrm{M}$. Specifically, the lowest concentration presented an insignificant inhibitory index of only $2.68 \pm 8.35 \%$, with a gradual increase until reaching a value of $87.34 \pm 5.50 \%$ for the highest tested concentration $(100 \mu \mathrm{M})(\mathrm{p}<0.05)$. As regards OA, a tendency of the inhibition of cell proliferation was observed (Fig. 2), which did not however, reach statistical significance ( $p=$ n.s.).

Effects of UA on SK-MEL-2 cell cycle progression. The aneuploid character of the SK-MEL-2 cells was demonstrated utilizing flow cytometric analysis, which indicated that the diploid cells represented $65 \%$ of the total number of cells and the aneuploid cells represented $35 \%$ of the total cell population. Therefore, the cell cycle passage of both the aneuploid and diploid cell populations is separately presented and demonstrated in Table I and Fig. 3 (dip, diploid cells; ane, aneuploidy cells). There was a significant shift in the cell cycle in both the diplod and the aneploid cells as compared with the controls. Of note, UA exerted effects on the cell cycle passage of aneuploid and diploid cells in a distinct manner. Thus, at $30 \mu \mathrm{M}$, there was an even distribution of diploid cells among the G0/G1, S and G2/M phase, whereas there was a massive distribution of aneuploid cells in the $\mathrm{G} 2 / \mathrm{M}$ phase.

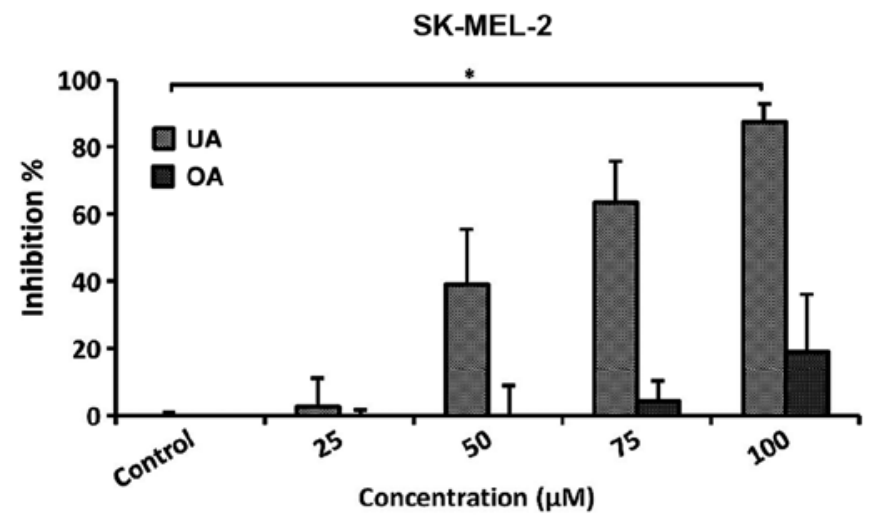

Figure 2. Effects of ursolic and oleanolic acid on SK-MEL-2 human melanoma cell proliferation. ${ }^{\mathrm{p}}<0.05$. UA, ursolic acid; OA, oleanolic acid.

An interesting fact is that for both the diploid and aneuploid populations, the exposure to $50 \mu \mathrm{M}$ UA resulted in S phase cell cycle arrest $(\mathrm{p}<0.05)$ (Table I). Exposure of the SK-MEL-2 cells to the concentration of $75 \mu \mathrm{M}$ led to the destruction of the cells and their detachment from the culture plate, not allowing for cell cycle analysis.

Effects of UA on SK-MEL-2 melanoma cell adhesion in the flow chamber assay. The flow chamber method represents an in vitro model which simulates the exposure of cells to the dynamical flux of fluids in a physiological environment (42). During the assay, the cells are subjected to mechanical stress (shear stress) of fluids. The method allows for the evaluation of theadhesive capacity to key molecules correlated with cancer progression, such as ICAM-1 and V-CAM 1, and enables the quantification of the cancer metastasis patterns of tumor cells $(43,44)$.

As shown in Fig. 4A, flow chamber analysis of the SK-MEL-2 cells demonstrated that the untreated cells remained attached to the VCAM substrate at the end of progressive exposure to shear stress at a percentage of $95.90 \%$. Data collected for the cells exposed to UA demonstrated slight alterations in the cell adhesive capacity (Fig. 4A). These alterations were not considered significant and, upon completing the experiment, a difference of only $4.70 \%$ compared with the adhesive ability of the controls was shown for a concentration of $30 \mu \mathrm{M}$ and only $5.30 \%$ for a concentration of $50 \mu \mathrm{M} \mathrm{UA}$.

Likewise, treatment with $30 \mu \mathrm{M}$ UA did not affect the ability of the cells to attach to the ICAM substrate ( $p=n . s$.) (Fig. 4B). Significant changes in cell adhesive ability were noted for the cells treated with $50 \mu \mathrm{M}$ UA. Indeed, upon the increase in shear stress (from $0.35 \mathrm{dyne} / \mathrm{cm}^{2}$ to $15 \mathrm{dyne} / \mathrm{cm}^{2}$ ) there was a proportional decrease in the number of attached cells with a difference of $24 \%$ lower cell number as compared with the controls $(\mathrm{p}<0.05)$.

Effects of UA and OA on angiogenesis utilizing CAM assay. The anti-angiogenic potential of UA and OA was assessed in an in vivo protocol by CAM assay. Normal angiogenesis during the high mitotic phase of endothelial cells and tumor-associated angiogenesis were investigated using the SK-MEL-2 melanoma cells. The evaluation was performed in ovo by means of stereomicroscopy. 
Table I. Effect of ursolic acid on cell cycle phases in the SK-MEL-2 melanoma cells.

Cell cycle distribution (\%)

\begin{tabular}{lcccccr}
\hline & \multicolumn{5}{c}{ SK-MEL-2 cells } \\
\cline { 2 - 7 } Treatment & G0/G1 dip & S dip & G2/M dip & G0/G1 ane & S ane & G2/M ane \\
\hline 0 & 44.66 & 46.65 & 8.67 & 30.45 & 57.74 & 11.79 \\
UA 30 $\mu \mathrm{M}$ & 39.23 & 33.92 & 35.29 & 18.54 & 0.10 & 81.45 \\
UA 50 $\mu \mathrm{M}$ & 31.51 & $58.99^{\mathrm{a}}$ & 9.49 & 17.48 & $78.01^{\mathrm{a}}$ & 4.50 \\
\hline
\end{tabular}

${ }^{\mathrm{a}} \mathrm{p}<0.05$, significant differences vs. control (no treatment). UA, ursolic acid; dip, diploid cells. ane, aneuploid cells.
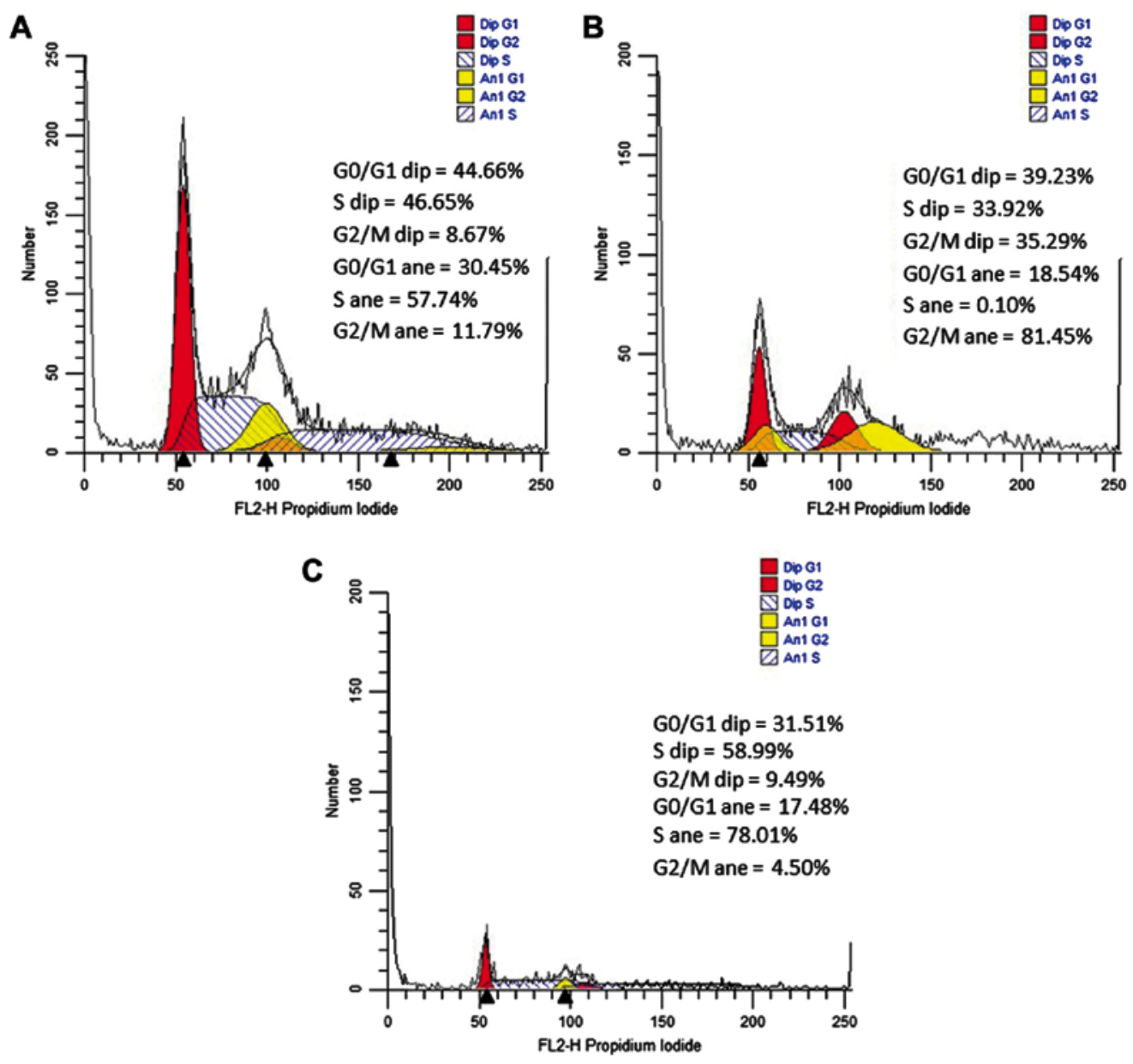

Figure 3. Cell cycle distribution in the SK-MEL-2 cells: (A) control, (B) cells treated with $30 \mu \mathrm{M} \mathrm{UA}$, and (C) cells treated with $50 \mu \mathrm{M}$ UA. UA, ursolic acid; dip, diploid cells; ane, aneuploidy cells.

The chicken embryo specimens (inoculated or not with tumor cells) exhibited good viability and survival rates with the test compounds, which were similar to those of the controls, e.g., around ED13 for all specimens. For the assessment of normal angiogenesis, modifications of the vascular plexus were observed throughout the experiment, and a gradual increase in the effects was noted, as shown in Fig. 5A-F. After 5 days of treatment, relevant images indicating the affected vessel architecture were registered and analyzed. Both OA and UA induced changes in the vascular network inducing a decrease in vessel number inside the application area, as compared with the blank specimens. A more prominent effect was noted with $\mathrm{OA}$, which induced a reduction in vascular density and several areas with very low number of fine capillaries were noted inside the ring (Fig. 5E and F).

An investigation of the angiogenic modulatory effects of the two triterpenoid compounds was also conducted in a melanoma model upon SK-MEL-2 cell inoculation to the CAM. The process was stereomicroscopically examined from the first day of the triterpene application onto previously inoculated 
A

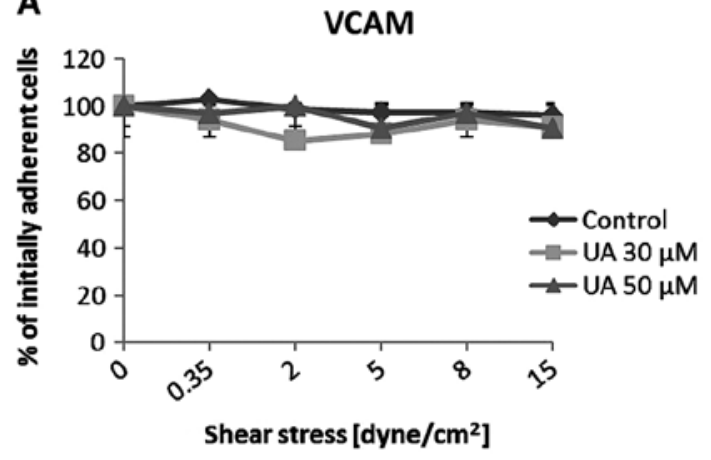

B

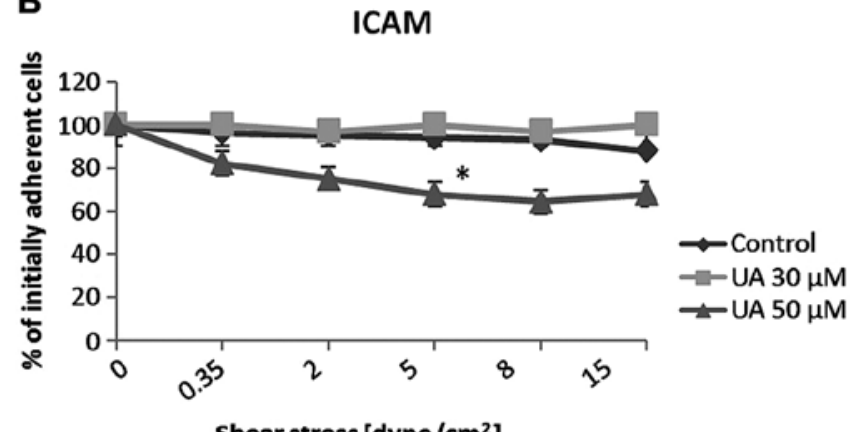

Figure 4. SK-MEL-2 cell adhesion to (A) VCAM and (B) ICAM substrates following treatment with UA. UA, ursolic acid; ICAM, intercellular adhesion molecule; VCAM, vascular cell adhesion molecule. ${ }^{*} \mathrm{p}<0.05$
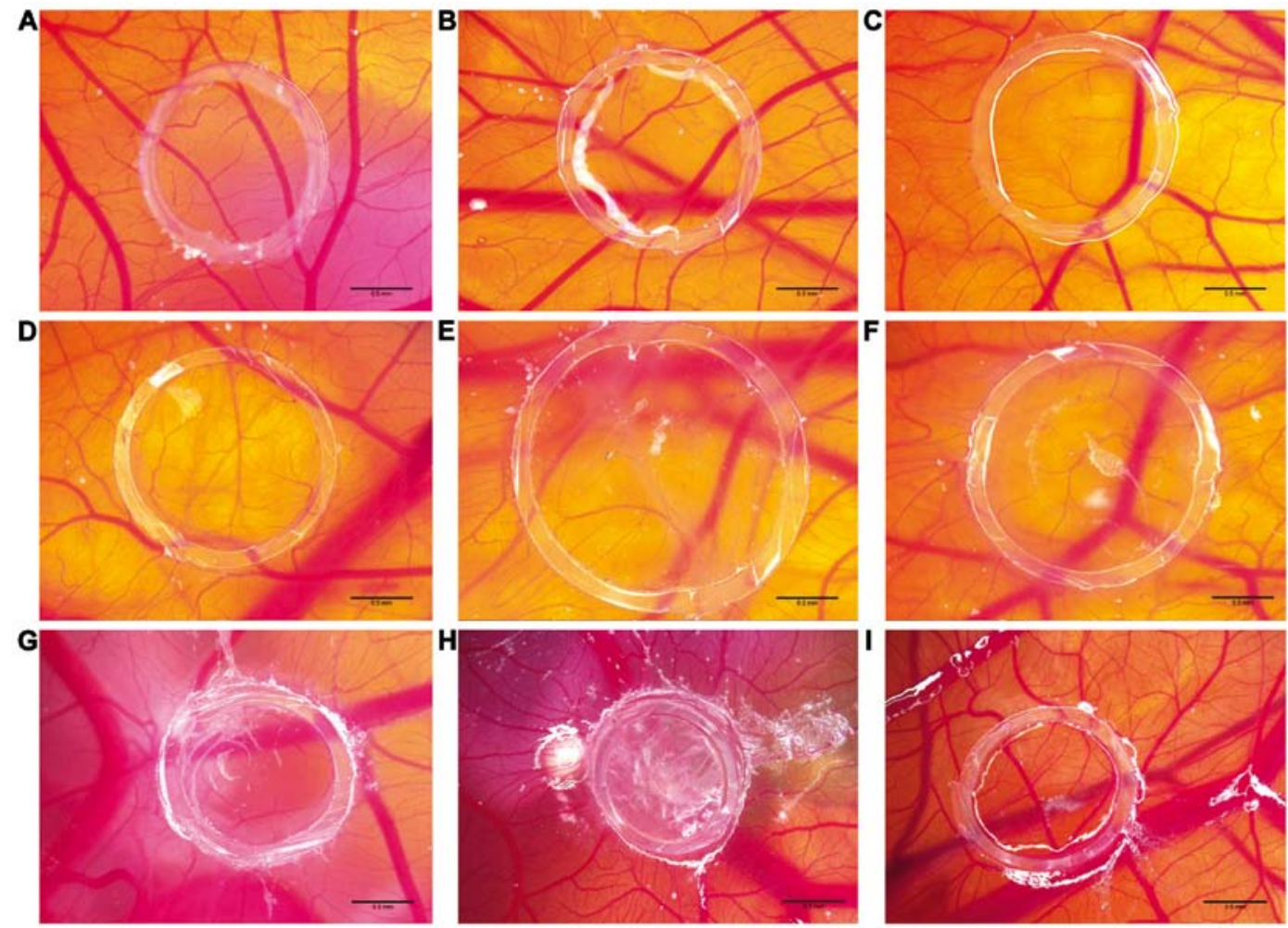

Figure 5. Effects of UA and OA on CAM assay. (A-C) Normal angiogenesis, with two doses of the test samples on ED9. (A) Blank (DMSO, 3\%), (B) UA, (C) OA. (D-F) Normal angiogenesis, with four doses of the test samples on ED11. (D) Blank (DMSO, 3\%), (E) UA, (F) OA. (G-I) SK-MEL-2 melanoma cells, with four doses of the test samples on ED13. (G) Control (cell medium), (H) SK-MEL-2 + UA, (I) SK-MEL-2 + OA. UA, ursolic acid; OA, oleanolic acid; CAM, chorioallantoic membrane; DMSO, dimethyl sulfoxide.

cells to the CAM. After 4 doses of triterpene solutions, relevant changes in the vascular arrangement surrounding the tumor cell implants were noted, accompanied by some alterations in the process of tumor growth. In correlation with the effects on the normal developing vascular plexus, OA exerted a significant effect on melanoma-associated angiogenesis, which seemed to have contributed to the growth of the tumor area inside the ring (Fig. 5I). The angiogenic reaction in the OA-treated CAMs was clearly reduced compared to both the control and the UA samples (Fig. 5G-I). The 'spokes wheel' type of vascular reaction can be observed converging towards the tumor site for the control and UA samples, but not for cells treated with OA (Fig. 5I). Conversely, UA did not severely impair the tumor-associated capillary density, the growth of melanoma cells was not inhibited (Fig. 5H), and the invasiveness of the melanoma cells was higher. Although the anti-angiogenic effects were more potent with OA than with UA, the metastatic potential was not inhibited with either agent. For the applied experimental conditions, the two triterpenes influenced, but did not inhibit the invasiveness of the SK-MEL-2 melanoma cells.

The morphometric evaluation of the angiogenic process by applying a 0-5 scale in correlation with the degree of vascular density also indicated that vessel growth was inhibited to a greater extent by OA during the rapid growing stage of the embryo, as well during the tumor growth process and related angiogenesis, using the SK-MEL-2 cell line. Treatment with OA led to a lower vascular density for the assessment 


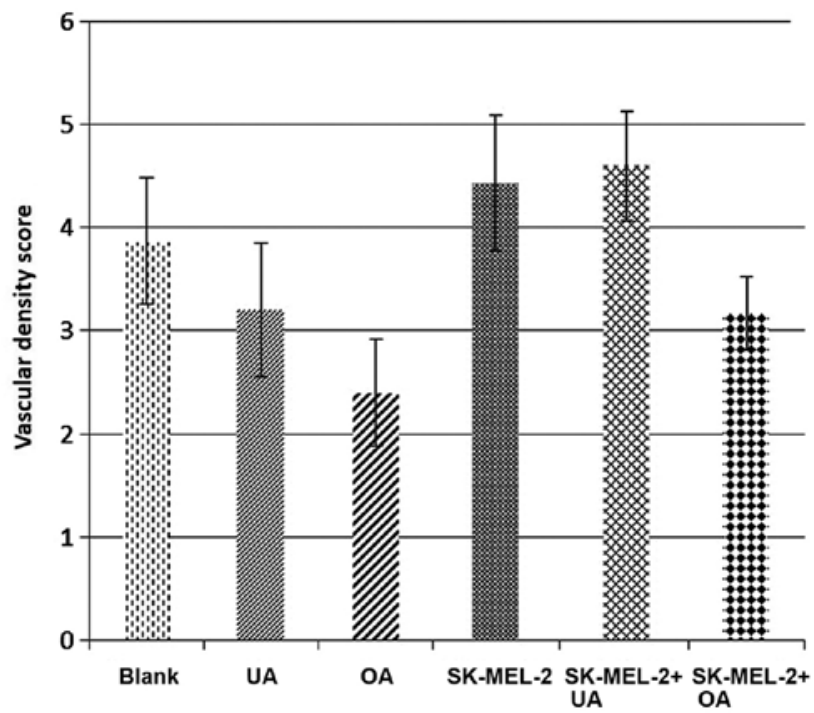

Figure 6. Vascular density scores induced by the test and control samples on CAM. Normal conditions and incubation with SK-MEL-2 melanoma cells. Data were assessed after four doses of UA and OA, using a 0-5 scale, by means of stereomicroscopy. CAM, chorioallantoic membrane; UA, ursolic acid; OA, oleanolic acid.

of melanoma-induced angiogenesis, while UA induced very similar or slightly higher values than those of the control specimens with only melanoma cells (Fig. 6).

\section{Discussion}

Proliferation and apoptosis constitute a very precise equilibrium in the healthy human body. Solid tumors represent a cluster of cells originating from a transformed founder cell with an increased capacity of proliferation, a decreased rate of apoptosis, an augmented metabolic rate, a high invasive capacity and an altered morphology $(45,46)$. The proliferative ability of cancer cells at a distant site is essential for metastasis, and difficulties in establishing secondary growth may explain why $<0.01 \%$ of circulating tumor cells (CTCs) actually form metastases (47).

In this study, we evaluated the potential use of two widely distributed natural triterpenoids as chemopreventive agents in the management of N-RAS-mutated melanoma, obtaining new data on the possible effects of UA and OA on the deregulated pathways of this type of melanoma not related to sun exposure. UA is known to induce apoptosis through the inhibition of the MEK and phosphoinositide 3-kinase (PI3K)/mTOR pathways, involved in a synergistic manner in N-RAS-mutated cancers (8), as demonstrated in prostate cancer (48) and leukemia cells (49), but not in melanoma cells. Less data are available on the modulation of these involved tyrosine kinase receptors by OA. Our results are indicative of the potential benefits of both compounds possibly in combination, for targeting the affected signaling keys of the N-RAS type of melanoma.

Our results revealed an intense anti-proliferative activity of UA in vitro on the human melanoma cell line, SK-MEL-2, as compared to the effects of OA, whose anti-proliferative activity was lower. This difference in potency was also highlighted by other research groups. Meng et al (48) reported a strong anti-proliferative potential for UA compared to UA in the case of Caco 2 colon cancer cells with $\mathrm{IC}_{50}$ values of $200 \mu \mathrm{M}$ for OA and $70 \mu \mathrm{M}$ for UA. Fulias et al (50) demonstrated that UA exerted a significant apoptotic activity against A2058 human melanoma cells, an effect that was not observed in the case of OA. In a separate study, our research group reported a superior activity of UA on several breast cancer tumor cell lines, as opposed to OA to which cancer cells were resistant (51).

The cytotoxic activity of triterpenoid compounds on in vitro melanoma assays shown in other studies has exhibited variability in potency when tested on different cell lines. Both OA and UA were shown to exert more potent effects on B164A5 cells as compared to the A431 and A375 melanoma cells (52). Due to their very low solubility in water, detrimental to their bioavailability, triterpenic acids were also investigated in different pharmaceutical formulations utilized to improve these parameters. Gamma-cyclodextrincomplexes with UA and OA were also tested for their biological activities, indicating better results than for the pure compounds on three melanoma cell lines (52). Some other triterpenoids have been tested under the form of myristoyl ester derivatives, which exhibited increased cytotoxicity values as compared to the compounds alone, on both A431 and A375 melanoma cells (53).

In normal cells, the cell cycle is tightly regulated. In cancer cells, due to genetic alterations, this process becomes disrupted, resulting in uncontrolled growth. Thus, the cell cycle represents the basis of tumor pathology and compounds proven to be active on cell cycle regulation may be candidates in anticancer therapy $(54,55)$.

Taking into account reports that show an anti-proliferative effect of UA on melanoma cells, which may be caused by alterations in cell cycle phases, we performed cell cycle analysis of SK-MEL-2 melanoma cells treated with UA, as previously described (56). In the present study, OA did not exert a significant decrease in cell proliferation; therefore, the activity on cell cycle events was investigated only for UA. Our study confirmed that the anti-proliferative effects of UA were mediated by alterations in the cell cycle, with exposure to $50 \mu \mathrm{M}$ of UA inducing arrest in the $\mathrm{S}$ phase. It has been previously demonstrated that UA induces cell cycles arrest at the G1 phase in MCF-7 and PC-3 cells $(57,58)$. Others have reported the involvement of $\mathrm{OA}$ in the $\mathrm{G} 2 / \mathrm{M}$ phase of the cell cycle by decreasing Cyclin Bi/cdc2 activity in HepG2 cells (18).

Although metastasis is widely regarded as an inefficient process, the majority of cancer patients succumb to the disease due to metastases rather than from their primary tumors. In the metastasis cascade, the adhesion of cancer cells to vascular endothelial cells through adhesion molecules is a crucial step (47). This intercellular interaction takes place in the context of a permanent mechanical shear stress of the bloodstream, where a balance between the hydrodynamic friction forces and the intercellular liaisons (cancer cells, endothelium) is established (59). Due to these pressures, only a small percentage of CTCs survives in order to metastasize (60). This is why the inhibition of intercellular interaction has become an important therapeutic target in the attenuation of metastases (61). Thus, tests which measure cell adhesion to surfaces/substrates are useful in the characterization of cellular superficial interactions (62). Investigations into tumor 
cell-endothelial contact formations have been based on similarities to the leukocyte-endothelial cell interactions during inflammation (61).

Since cell adhesion and cell interaction are key steps in the metastatic process, in this study, we aimed to examine the influence of UA, the most active compound, on cell adhesive capacity. Using the flow chamber protocol, we observed that incubating the SK-MEL-2 cells with high concentrations of UA $(50 \mu \mathrm{M})$ led to a decreased adhesion capacity to the ICAM substrate, without however, influencing the adherence capacity of the cells to VCAM.

VCAM 1 (also known as CD106) is an adhesion molecule which mediates the adhesion of leukocytes to the endothelium. It is expressed by endothelial cells following stimulation by cytokines. It has been reported that colorectal cancer cells adhere to the vascular endothelium by binding to VCAM-1 (63). In addition, some types of melanoma cells are known to adhere to the endothelium through VCAM-1 (64). ICAM-1 (also known as CD54) is a transmembrane glycoprotein, part of the immunoglobulin family, and is widely expressed by hematopoietic and non-hematopoietic cells, including endothelial cells, leukocytes, fibroblasts or cancer cells; however, under cytokine stimulation it may be expressed on every human cell type (65). It is known that the inhibition of ICAM-1 expression on melanoma cells may reduce their metastatic potential (66).

In order to obtain more data regarding the possible implication of the two selected triterpenoid compounds on the aggressive metastatic process induced by melanoma cells with an N-RAS mutation, in conjunction to the in vitro studies, we chose to apply an in vivo method, CAM assay. The choice of the protocol was based on multiple advantages, such as low costs, consumed time and number of sacrificed animals that render this assay effective for pre-screening model studies (67).

Following stereomicroscopic evaluation, we observed that the two analyzed compounds functioned differently on the in vivo developing vascular system and the tumor microenvironment. OA exerted more potent effects as compared to UA, on the normal process of angiogenesis, but without influencing the viability of the embryos. Inside the application ring, OA induced a decrease in the number of newly formed capillaries during a highly angiogenic interval (i.e., EDD7-EDD11) (68). The vascular branching pattern was also influenced outside the application site, but to a lower extent compared to UA.

The two triterpenoids also differently influenced the development of in vivo SK-MEL-2 melanoma on the chick embryo CAM. UA induced a lower impairment of the tumor progress, without important limitations in tumor growth, which was in contrast with the in vitro results of the SK-MEL-2 cytotoxicity assay. Moreover, tumor angiogenesis was not inhibited. Therefore, the invasiveness of the tumor was not restricted, showing extended areas of secondary tumors outside the application spot. At a concentration of $30 \mu \mathrm{M}$, it seemed that UA had stimulatory implications on tumor progression, compared with the untreated control CAMs. Conversely, OA, the compound considered to exert less potent effects on tumor growth in vitro on the SK-MEL-2 cells, limited to a greater extent the growth of tumor cells inside the ring, in vivo.

Other studies have reported the anti-angiogenic effects of the two compounds. Cárdenas et al (69) reported the in vitro effects of UA on angiogenesis, proving that it inhibited certain stages of angiogenesis (proliferation, migration and endothelial cell differentiation), while stimulating other stages (extracellular matrix degradation by MMP-2 and urokinases). Still, both compounds were shown to inhibit the production of vascular endothelial growth factor (VEGF), one of the factors responsible for angiogenesis.

Lin et al (70) reported the anti-angiogenic effects of UA in vitro and in vivo in colorectal cancer. It reduced intratumoral microvascular density in mice with colorectal cancer, as well as the number of blood vessels in the CAM pattern, and it also inhibited the expression of certain angiogenic factors. Both UA and OA exerted anti-angiogenic effects on liver cancer cells (71).

It has been reported that VEGF-induced angiogenesis can be modulated by ICAM (72), a cellular adhesion molecule with high impact in developing recurrence, invasion and metastatic process (73), its production being inhibited by the two studied acids (28). As we only tested UA for this effect, and it showed an anti-adhesive potential, particularly towards I-CAM molecules in vitro, we considered that the invasive pattern of the SK-MEL2 cells incubated with UA on the CAM assay was rather determined by a different pathway.

As regards the anti-angiogenic effects of $30 \mu \mathrm{M}$ UA and OA on normal CAM, our results obtained for UA were contrary to those reported by Cárdenas et al (69), who observed a reduction in angiogenesis in 50\% of the eggs treated with $20 \mu \mathrm{mol} \mathrm{UA.} \mathrm{In}$ addition, Sohn et al (74) reported an increased anti-angiogenic potential for UA, compared to $\mathrm{OA}$, with $\mathrm{IC}_{50}$ values of 5 and $20 \mu \mathrm{M}$ for UA and OA, respectively. However, both studies were performed using a bovine aortic endothelial cell CAM model. On the other hand, Kiran et al (75) reported an impairment of angiogenic modulators after the administration of UA at concentrations $>10 \mu \mathrm{M}$, while lower concentrations did not affect the angiogenesis of human umbilical vein endothelial cells (HUVECs). No data were found regarding the effects of OA or UA in a SK-MEL-2 melanoma model on the CAM assay.

In conclusion, the two tested triterpenoid acids, UA and OA, exerted differential effects in vitro and in vivo on SK-MEL-2 melanoma cells. UA exerted a significant dose-dependent anti-proliferative effect in vitro, compared to OA. The cytotoxic effects in vitro on the melanoma cells were determined by the alterations in the cell cycle phases by UA that induced cell arrest in the $\mathrm{S}$ phase. Moreover, UA may contribute to the capacity of SK-MEL-2 melanoma cell invasiveness by limiting the cell adhesion capacity to ICAM molecules, but not influencing the adhesion to VCAM.

Assessing the effects of the two triterpenoids in vivo using SK-MEL-2 melanoma cells on a CAM model, our results revealed the potential impairment of the invasive and angiogenic tumor process to a greater extent for $\mathrm{OA}$ compared to UA. These elements are suggestive of testing the two compounds as a mixture, with possible synergic or additive effects on blood vessels and tumor cells. Even though further studies are warranted to confirm our effects, the easily available compounds from accessible natural sources, UA and OA, may be considered effective chemopreventive agents for possible use in the management of N-RAS-mutated melanoma. 


\section{Acknowledgements}

This study was supported by an Internal grant at UMFT 'Victor Babes', Grant III-C5-PCFI-2017/2018-04 ROINEXTRAMAM; Project director, Avram Stefana.

\section{References}

1. American Cancer Society: Key statistics for melanoma skin cancer. https://www.cancer.org/cancer/melanoma-skin-cancer/ about/key-statistics.html. Accessed March 17, 2017.

2. Schadendorf D, Fisher DE, Garbe C, Gershenwald JE, Grob JJ, Halpern A, Herlyn M, Marchetti MA, McArthur G, Ribas A, et al: Melanoma. Nat Rev Dis Primers 1: 15003, 2015.

3. Danciu C, Oprean C, Coricovac DE, Andreea C, Cimpean A, Radeke $\mathrm{H}$, Soica $\mathrm{C}$ and Dehelean $\mathrm{C}$ : Behaviour of four different B16 murine melanoma cell sublines: C57BL/6J skin. Int J Exp Pathol 96: 73-80, 2015.

4. Wu S and Singh RK: Resistance to chemotherapy and molecularly targeted therapies: Rationale for combination therapy in malignant melanoma. Curr Mol Med 11: 553-563, 2011.

5. Mouawad R, Sebert M, Michels J, Bloch J, Spano JP and Khayat D: Treatment for metastatic malignant melanoma: Old drugs and new strategies. Crit Rev Oncol Hematol 74: 27-39, 2010.

6. Khan MK, Khan N, Almasan A and Macklis R: Future of radiation therapy for malignant melanoma in an era of newer, more effective biological agents. Onco Targets Ther 4: 137-148, 2011.

7. Finn L, Markovic SN and Joseph RW: Therapy for metastatic melanoma: The past, present, and future. BMC Med 10: 23, 2012.

8. Posch C, Moslehi H, Feeney L, Green GA, Ebaee A, Feichtenschlager V, Chong K, Peng L, Dimon MT, Phillips T, et al: Combined targeting of $\mathrm{MEK}$ and $\mathrm{PI} 3 \mathrm{~K} / \mathrm{mTOR}$ effector pathways is necessary to effectively inhibit NRAS mutant melanoma in vitro and in vivo. Proc Natl Acad Sci USA 110: 4015-4020, 2013.

9. Johnson DB and Sosman JA: Update on the targeted therapy of melanoma. Curr Treat Options Oncol 14: 280-292, 2013.

10. Posch C, Vujic I, Monshi B, Sanlorenzo M, Weihsengruber F, Rappersberger K and Ortiz-Urda S: Searching for the Chokehold of NRAS Mutant Melanoma. J Invest Dermatol 136: 1330-1336, 2016.

11. Jiang Y-L and Liu Z-P: Natural products as anti-invasive and anti-metastatic agents. Curr Med Chem 18: 808-829, 2011.

12. Cragg GM and Pezzuto JM: Natural products as a vital source for the discovery of cancer chemotherapeutic and chemopreventive agents. Med Princ Pract 25 (Suppl 2): 41-59, 2016

13. Folkman J, Merler E, Abernathy C and Williams G: Isolation of a tumor factor responsible for angiogenesis. J Exp Med 133 275-288, 1971.

14. Ejaz S: Anwar K, Taj R and Ashraf M: A novel link between angiogenesis and natural products: Anti-angiogenic effects of Opuntia dillenii. Cent Eur J Biol 9: 298-308, 2013.

15. Li WW, Li VW, Hutnik M and Chiou AS: Tumor angiogenesis as a target for dietary cancer prevention. J Oncol 2012: 879623, 2012.

16. Hata K, Hori K and Takahashi S: Differentiation- and apoptosis-inducing activities by pentacyclic triterpenes on a mouse melanoma cell line. J Nat Prod 65: 645-648, 2002.

17. Allouche Y, Warleta F, Campos M, Sánchez-Quesada C, Uceda M, Beltrán G and Gaforio JJ: Antioxidant, antiproliferative, and pro-apoptotic capacities of pentacyclic triterpenes found in the skin of olives on MCF-7 human breast cancer cells and their effects on DNA damage. J Agric Food Chem 59: 121-130, 2011.

18. Zhang W, Men X and Lei P: Review on anti-tumor effect of triterpene acid compounds. J Cancer Res Ther 10 (Suppl 1): 14-19, 2014.

19. Chudzik M, Korzonek-Szlacheta I and Król W: Triterpenes as potentially cytotoxic compounds. Molecules 20: 1610-1625, 2015.

20. Mencherini T, Picerno P, Scesa C and Aquino R: Triterpene, antioxidant, and antimicrobial compounds from Melissa officinalis. J Nat Prod 70: 1889-1894, 2007.

21. Wójciak-Kosior M, Sowa I, Kocjan R and Nowac R: Effect of different extraction techniques on quantification of oleanolic and ursolic acid in Lamii albi flos. Ind Crops Prod 44: 373-377, 2013.

22. J C Furtado NA, Pirson L, Edelberg H, M Miranda L, LoiraPastoriza C, Preat V, Larondelle Y and André CM: Pentacyclic triterpene bioavailability: An overview of in vitro and in vivo studies. Molecules 22: E400, 2017.
23. Ziberna L, Samec D, Mocan A, Nabavi SF, Bishayee A, Farooqi AA, Sureda A and Nabavi SM: Oleanolic acid alters multiple cell signaling pathways: implication in cancer prevention and therapy. Int J Mol Sci 18: E643, 2017

24. Ikeda Y, Murakami A and Ohigashi H: Ursolic acid: An anti- and pro-inflammatory triterpenoid. Mol Nutr Food Res 52: 26-42, 2008.

25. Bishayee A, Ahmed S, Brankov N and Perloff M: Triterpenoids as potential agents for the chemoprevention and therapy of breast cancer. Front Biosci (Landmark Ed) 16: 980-996, 2011.

26. Meng QX, Roubin RH and Hanrahan JR: Ethnopharmacological and bioactivity guided investigation of five TCM anticancer herbs. J Ethnopharmacol 148: 229-238, 2013.

27. Li J, Guo WJ and Yang QY: Effects of ursolic acid and oleanolic acid on human colon carcinoma cell line HCT15. World J Gastroenterol 8: 493-495, 2002.

28. Yan SL, Huang CY, Wu ST and Yin MC: Oleanolic acid and ursolic acid induce apoptosis in four human liver cancer cell lines. Toxicol In Vitro 24: 842-848, 2010

29. Lee IK, Kim DH, Lee SY, Kim KR, Choi SU, Hong JK, Lee JH, Park YH and Lee KR: Triterpenoic acids of Prunella vulgaris var. lilacina and their cytotoxic activities in vitro. Arch Pharm Res 31: 1578-1583, 2008.

30. George VC, Naveen Kumar DR, Suresh PK and Kumar A: Oleanolic acid inhibits cell growth and induces apoptosis in A375 melanoma cells. Biomed Prev Nutr 4: 95-99, 2014.

31. Oprean C, Mioc M, Csányi E, Ambrus R, Bojin F, Tatu C, Cristea M, Ivan A, Danciu C, Dehelean C, et al: Improvement of ursolic and oleanolic acids' antitumor activity by complexation with hydrophilic cyclodextrins. Biomed Pharmacother 83: 1095-1104, 2016.

32. Avram S, Avram S, Crisan L, Pacureanu L, Kurunczi L and Bora A: Self-Organizing Map Classif Model. Rev Roum Chim 60: 167-173, 2015.

33. Avram SI, Pacureanu LM, Bora A, Crisan L, Avram S and Kurunczi L: ColBioS-FlavRC: A collection of bioselective flavonoids and related compounds filtered from high-throughput screening outcomes. J Chem Inf Model 54: 2360-2370, 2014.

34. Bora A, Avram S, Ciucanu I, Raica M and Avram S: Predictive models for fast and effective profiling of kinase inhibitors. J Chem Inf Model 56: 895-905, 2016.

35. Mu DW, Guo HQ, Zhou GB, Li JY and Su B: Oleanolic acid suppresses the proliferation of human bladder cancer by Akt/mTOR/S6K and ERK1/2 signaling. Int J Clin Exp Pathol 8: 13864-13870, 2015.

36. Rufino-Palomares EE, Pérez-Jiménez A, Reyes-Zurita FJ, García-Salguero L, Mokhtari K, Herrera-Merchán A, Medina PP Peragón J and Lupiáñez JA: Anti-cancer and anti-angiogenic properties of various natural pentacyclic tri-terpenoids and some of their chemical derivatives. Curr Org Chem 19: 919-947, 2015.

37. Laszczyk MN: Pentacyclic triterpenes of the lupane, oleanane and ursane group as tools in cancer therapy. Planta Med 75: $1549-1560,2009$

38. Shanmugam MK, Nguyen AH, Kumar AP, Tan BKH and Sethi G: Targeted inhibition of tumor proliferation, survival, and metastasis by pentacyclic triterpenoids: Potential role in prevention and therapy of cancer. Cancer Lett 320: 158-170, 2012.

39. Shan J, Xuan Y, Zhang Q, Zhu C, Liu Z and Zhang S: Ursolic acid synergistically enhances the therapeutic effects of oxaliplatin in colorectal cancer. Protein Cell 7: 571-585, 2016.

40. Ribatti D: The chick embryo chorioallantoic membrane in the study of tumor angiogenesis. Rom J Morphol Embryol 49: 131-135, 2008

41. Ribatti D: The Chick Embryo Chorioallantoic Membrane in the Study of Angiogenesis and Metastasis. 1st edition. Springer, Netherlands, 2010.

42. Bacabac RG, Smit TH, Cowin SC, Van Loon JJ, Nieuwstadt FT, Heethaar R and Klein-Nulend J: Dynamic shear stress in parallel-plate flow chambers. J Biomech 38: 159-167, 2005.

43. Zhang Y and Neelamegham S: An analysis tool to quantify the efficiency of cell tethering and firm-adhesion in the parallel-plate flow chamber. J Immunol Methods 278: 305-317, 2003.

44. Zhao L, Liao FL, Han D and Zhou H: Application of parallel-plate flow chamber in cancer research. Bull Acad Mil Med Sci 33: 482-485, 2009

45. Griffiths AJF, Miller JH, Suzuki DT, Lewontin RC and Gelbart WM: Cancer: The Genetics Of Aberrant Cell Control. An Introduction to Genetic Analysis. 7th edition. W.H. Freeman \& Co, New York, NY, 2000.

46. Pfarr K, Danciu C, Arlt O, Neske C, Dehelean C, Pfeilschifter JM and Radeke $\mathrm{HH}$ : Simultaneous and dose dependent melanoma cytotoxic and immune stimulatory activity of betulin. PLoS One 10: e0118802, 2015 
47. Wong SY and Hynes RO: Lymphatic or hematogenous dissemination: How does a metastatic tumor cell decide? Cell Cycle 5: 812-817, 2006.

48. Meng Y, Lin ZM, Ge N, Zhang DL, Huang J and Kong F: Ursolic acid induces apoptosis of prostate cancer cells via the PI3K/ Akt/mTOR pathway. Am J Chin Med 43: 1471-1486, 2015.

49. Beagle B and Fruman DA: The PI3K-AKT-mTOR signaling network in AML. In: Targeted Therapy of Acute Myeloid Leukemia. Andreeff M (ed). Springer, New York, NY, pp335-362, 2015.

50. Fuliaş A,Ledeți I, Vlase G, Vlase T, Şoica C,Dehelean C, Oprean C, Bojin F, Şuta LM, Bercean V and Avram S: Thermal degradation, kinetic analysis, and apoptosis induction in human melanoma for oleanolic and ursolic acids. J Therm Anal Calorim 125: 759-768, 2016.

51. Oprean C, Zambori C, Borcan F, Soica C, Zupko I, Minorics R, Bojin F, Ambrus R, Muntean D, Danciu C, et al: Anti-proliferative and antibacterial in vitro evaluation of the polyurethane nanostructures incorporating pentacyclic triterpenes. Pharm Biol 54 2714-2722, 2016

52. Trandafirescu C, Antal D, Soica C,Zupko I, Minorics R, Ambrus R, Borcan F, Oprean C, Danciu C, Avram S, et al: Cyclodextrin complexes of oleanolic and ursolic acid physico-chemical and biological preliminary evaluation. Rev Chim 65: 1163-1167, 2014

53. Pinzaru I, Trandafirescu C, Szabadai Z, Mioc M, Ledeti I, Coricovac D, Ciurlea S, Ghiulai RM, Crainiceanu Z and Simu G: Synthesis and biological evaluation of some pentacyclic lupane triterpenoid esters. Rev Chim 65: 848-851, 2014.

54. wiseGEEK: What is cell cycle arrest? http://www.wisegeek.com/ what-is-cell-cycle-arrest.htm. Accessed Aug 15, 2017.

55. Cyclacel: Cell cycle in cancer. http://www.cyclacel.com/research science_cell-cycle.shtml. Accessed Aug 17, 2017.

56. Chakravarti B, Maurya R, Siddiqui JA, Bid HK, Rajendran SM, Yadav PP and Konwar R: In vitro anti-breast cancer activity of ethanolic extract of Wrightia tomentosa: Role of pro-apoptotic effects of oleanolic acid and urosolic acid. J Ethnopharmacol 142: 72-79, 2012.

57. Es-Saady D, Simon A, Jayat-Vignoles C, Chulia AJ and Delage C: MCF-7 cell cycle arrested at G1 through ursolic acid, and increased reduction of tetrazolium salts. Anticancer Res 16: 481-486, 1996.

58. Park JH, Kwon H-Y, Sohn EJ, Kim KA, Kim B, Jeong SJ, Song JH, Koo JS and Kim S-H: Inhibition of Wnt/ $\beta$-catenin signaling mediates ursolic acid-induced apoptosis in PC-3 prostate cancer cells. Pharmacol Rep 65: 1366-1374, 2013.

59. Lawrence MB, McIntire LV and Eskin SG: Effect of flow on polymorphonuclear leukocyte/endothelial cell adhesion. Blood 70: 1284-1290, 1987.

60. Mitchell MJ and King MR: Computational and experimental models of cancer cell response to fluid shear stress. Front Oncol 3 : 44, 2013.
61. Bendas G and Borsig L: Cancer cell adhesion and metastasis: selectins, integrins, and the inhibitory potential of heparins. Int J Cell Biol 2012: 676731, 2012

62. Olivier LA and Truskey GA: A numerical analysis of forces exerted by laminar flow on spreading cells in a parallel plate flow chamber assay. Biotechnol Bioeng 42: 963-973, 1993.

63. Chen C, Zhang Q, Liu S, Parajuli KR, Qu Y, Mei J, Chen Z, Zhang H, Khismatullin DB and You Z: IL-17 and insulin/IGF1 enhance adhesion of prostate cancer cells to vascular endothelia cells through CD44-VCAM-1 interaction. Prostate 75: 883-895, 2015.

64. Eibl RH and Benoit M: Molecular resolution of cell adhesion forces. IEE Proc, Nanobiotechnol 151: 128-132, 2004

65. Paschos KA, Canovas D and Bird NC: The role of cell adhesion molecules in the progression of colorectal cancer and the development of liver metastasis. Cell Signal 21: 665-674, 2009.

66. Zhang P, Goodrich C, Fu C and Dong C: Melanoma upregulates ICAM-1 expression on endothelial cells through engagement of tumor CD44 with endothelial E-selectin and activation of a PKC $\alpha$-p38-SP-1 pathway. FASEB J 28: 4591-4609, 2014.

67. Nowak-Sliwinska P, Segura T and Iruela-Arispe ML: The chicken chorioallantoic membrane model in biology, medicine and bioengineering. Angiogenesis 17: 779-804, 2014.

68. Deryugina EI and Quigley JP: Chick embryo chorioallantoic membrane model systems to study and visualize human tumor cell metastasis. Histochem Cell Biol 130: 1119-1130, 2008.

69. Cárdenas C, Quesada AR and Medina MA: Effects of ursolic acid on different steps of the angiogenic process. Biochem Biophys Res Commun 320: 402-408, 2004.

70. Lin J, Chen Y, Wei L, Hong Z, Sferra TJ and Peng J: Ursolic acid inhibits colorectal cancer angiogenesis through suppression of multiple signaling pathways. Int J Oncol 43: 1666-1674, 2013.

71. Lin CC, Huang CY, Mong MC, Chan CY and Yin MC: Antiangiogenic potential of three triterpenic acids in human liver cancer cells. J Agric Food Chem 59: 755-762, 2011.

72. Sun JJ, Zhou XD, Liu YK, Tang ZY, Feng JX, Zhou G, Xue Q and Chen J: Invasion and metastasis of liver cancer: Expression of intercellular adhesion molecule 1. J Cancer Res Clin Oncol 125: 28-34, 1999.

73. Gho YS, Kim PN, Li HC, Elkin M and Kleinman HK: Stimulation of tumor growth by human soluble intercellular adhesion molecule-1. Cancer Res 61: 4253-4257, 2001.

74. Sohn KH, Lee HY, Chung HY, Young HS, Yi SY and Kim KW: Anti-angiogenic activity of triterpene acids. Cancer Lett 94: 213-218, 1995.

75. Kiran MS, Viji RI, Sameer Kumar VB and Sudhakaran PR: Modulation of angiogenic factors by ursolic acid. Biochem Biophys Res Commun 371: 556-560, 2008. 